\title{
AN ANALYSIS OF COMMON APPLICATIONS ON HEDONIC PRICING MODEL IN VALUING ECOSYSTEM SERVICES: SIMILARITIES AND DIFFERENCE BETWEEN EUROPE, US, AND CHINA
}

\author{
Xuanfei Zhang ${ }^{*}{ }^{\mathbb{M}}$ \\ ${ }^{* 1}$ Department of Applied Economics and Management, Cornell University, United States, New York
}

DOI: https://doi.org/10.29121/ijetmr.v8.i1.2021.849

Article Citation: Xuanfei Zhang. (2021). AN ANALYSIS OF COMMON APPLICATIONS ON HEDONIC PRICING MODEL IN VALUING ECOSYSTEM SERVICES: SIMILARITIES AND DIFFERENCE BETWEEN EUROPE, US, AND CHINA. International Journal of Engineering Technologies and Management Research, 8(1), 1-11. https://doi.org/10.29121/ijetmr.v8 .i1.2021.849

Published Date: 23 January 2021

Keywords:

Hedonic Pricing Model

Ecosystem Services

\begin{abstract}
The study made a comparison with the common applications on the hedonic pricing model that valuing ecosystem services between Europe, the United States, and China. By analyzing various reasons impacting housing prices, cultural and historical backgrounds played roles in the realworld applications.
\end{abstract}

\section{INTRODUCTION}

The methodology of valuation on ecosystem services had long been an issue in the field of environmental economics. The Hedonic pricing model, under the Revealed preference approaches, is used to estimate the ecosystem value based on physical characteristics. For instance, it could be used to estimate the value of houses as a function of variables including proximity to open space. Once estimated, a certain value of preserving open space could be calculated based on total higher property values permitted (David R. Lee, 2020). The housing prices or the price of certain properties could be estimated by the marginal contribution of different attributes to property value, including, aesthetic view, water quality, available recreational activities, parking lot, the structure of houses, around zoning design, road design, and city planning. All these factors are related to determining housing prices. Species habitat regulating services are included as well (David R. Lee, 2020). In analyzing the factors impacting housing prices, especially how the surrounding green spaces, and environmental amenities playing roles, vary between countries. In this paper, I am going to take a closer look at various cases in Europe, the United States, and China, by comparing some similarities and differences. Additionally, I would like to draw some interesting discussion regarding the future tendency of how the green space impacting the housing prices in China might be changed after the current epidemic of COVID-19.

One of the essential steps that people made in their life is buying a house. Not only representing the feeling of belongingness, but people will be able to stabilize after owning a house in the regions they are living in. Especially for those who live and work in big cities, it always remains an internal topic over the selection of houses. The reasons

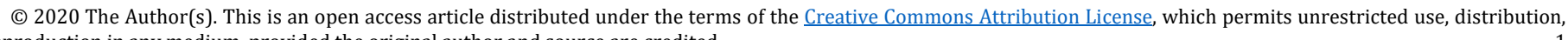
and reproduction in any medium, provided the original author and source are credited. 
for people to decide the places and characteristics of houses vary. Some of the reasons are socio-economic related, and some are culture related.

\section{LITERATURE REVIEW}

\subsection{EUROPE}

Hedonic pricing analysis helps to measure the preferences towards different attributes in impacting the housing prices, based on a large amount of real estate data. It includes some variables that are not easy to capture and evaluate, for instance like a nice and quiet environment, distances to the city center, or the recreational available activities of the nearby green space (Czembrowski and Kronenberg, 2016). Compared to studies on the hedonic pricing model application done in some western countries, not many pieces of research were conducted in Central and Eastern Europe areas (Brander \& Koetse, 2011). Aiming to find the influence of different types of green space on housing prices in Lodz, the largest city in Poland, Czembrowski and Kronenberg did they're by dividing groups of green spaces into nine categories, including small parks and forests (smaller than 18000 square meters), medium parks and forests (1800 to 200000 square meters), large parks and forests (larger than 2000000 square meters), the single largest forest (over 13000000 square meters), cemeteries, and allotment gardens. The proxy of the more general ambient condition was to set a percentage of greenery in a 500 meters radius. The area of green land in Lodz was designed not the same in terms of size and distribution, making the city a good case study example (Czembrowski and Kronenberg, 2016).

The result of the study revealed the relationship between housing prices and surrounding environmental attributes. As for the proximity to cemeteries, people who were thinking about the certain property would regard it poorly with shorter distances. However, when it came to forest and park, alongside some previous study, the larger exposure of the open green space resulted in better property value. After applying the percentage of greenery and different types and sizes of the green space, Czembrowski and Kronenberg found that the accessibility in Lodz improved in property value from open green spaces, as well as the general environmental design of the city. To be more specific, they suggested that the existence of forests played a crucial role in explaining the surrounding housing price, like a small forest. Though some areas of green land might be difficult to capture with size and types, the small forest could still be estimated as one of the strongest impacting factors to the value of the property in Lodz (Czembrowski and Kronenberg, 2016).

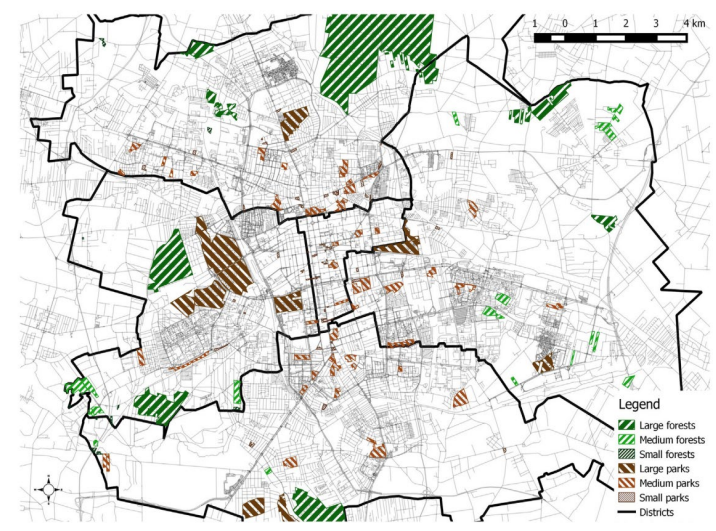

(Parks and forests in Lodz. Source: Czembrowski, P., \& Kronenberg, J. (2016). Hedonic pricing and different urban green space types and sizes: Insights into the discussion on valuing ecosystem services. Landscape and Urban Planning, 146, 11-19. https://doi-org.proxy.library.cornell.edu/10.1016/j.landurbplan.2015.10.005)

Nevertheless, cemeteries had been shown in the results that, not welcomed by many buyers in Lodz. In other words, having cemeteries near housing would be viewed as not as good impacting housing prices. The same finding occurred in some other studies as well. The existence of the cemetery would negatively be impacting the price of a property in Hong Kong (Tse and Love, 2000). Besides regions in Asia, some places in the United States indicated similar results. Anderson and West founded in the year of 2006 with a negative and lower influence on real estate 
pricing from the proximity to cemeteries in the Minneapolis-St. Paul metropolitan area (Anderson and West, 2006). Besides, the housing prices were found negatively related to the distances to the closest cemetery in Portland, Oregon (Lutzenhiser and Netusil, 2001). When looking at the places for cemeteries, some are located near school and public construction areas. Comparatively speaking, these places are more open regarding the sizes and places in Asian countries. It would be not easy to witness cemeteries in open areas, but rather, in the faraway mountains or countryside. People would choose to visit past relatives during a specific period of time. In other words, though the influences from cemeteries were found negative to the housing prices; some cultural aspects still played roles in causing the differences.

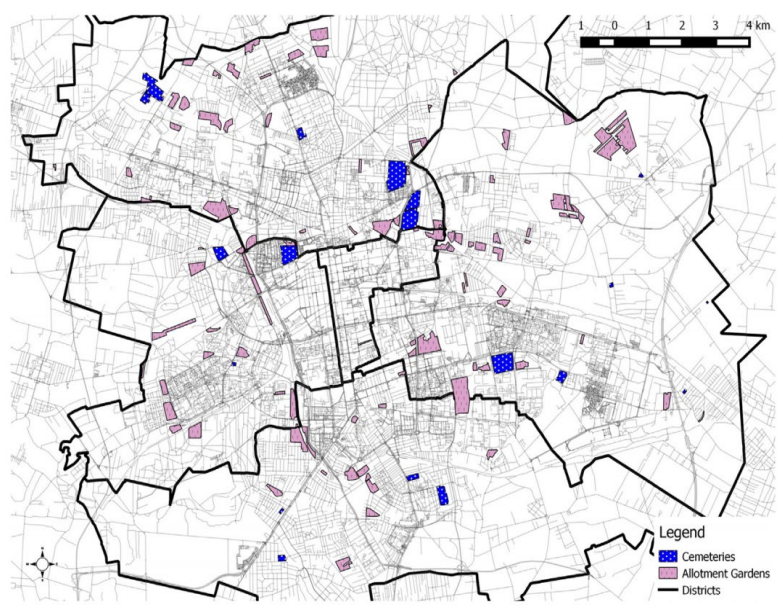

(Cemeteries and allotment gardens in Lodz. Source: Czembrowski, P., \& Kronenberg, J. (2016). Hedonic pricing and different urban green space types and sizes: Insights into the discussion on valuing ecosystem services. Landscape and Urban Planning, 146, 11-19.

https://doiorg.proxy.library.cornell.edu/10.1016/j.landurbplan.2015.10.005)

As for the hedonic pricing model application, Czembrowski and Kronenberg argued that it might not be strong enough to determine the impact of individual ecosystem services. That might be due to the difficulties of measurement, and separation of the context of the hedonic pricing model and the concept of ecosystem services (Czembrowski and Kronenberg, 2016).

What's more, a hedonic pricing simulation approach was applied in analyzing the socio-economic impacts of green space, urban residential, and road infrastructure projects in Lyon, cities in France. Roebeling et al study the additional value of the green space with the application of a hedonic pricing simulation model. It argued that developing urban green space brought some aspects of risk, including potentially impacting profitable residential areas, or generating waste-disposal sites. In some cases, green spaces are regarded as secondary development on the urban city planning agendas since the maintenance and habitation would not be viewed as urgent in the shortrun (Roebeling et al, 2017). Nevertheless, the benefits of getting from the open-access of green space are huge. In terms of improving the aesthetic design of the city, the proportion of green space coverage obtains both physical and psychological advantages. Some past studies indicated that there has been a growing number of arguments stating that green space helps to provide important ecosystem services, which stimulate surrounding housing prices and avoid flooding issues in the long term.

The Sustainable Urbanizing Landscape Development (SULD), the scenario simulation decision support tool was applied in this study (Roebeling et al, 2007). This tool helped with future planning and rehabilitation of urban spaces by constructing additional analysis over the values of environmental amenities that do not yet exist, or not available data sets over the sailing prices of certain properties, based on the original hedonic pricing model. In the city of Lyon, water management and flood control became a problem in terms of difficulties in maintenance and infrastructures. The Lyon Confluence Project was designed to deal with the issue of poor conditions with pollution during the storm event, overflow devices, and the presence of rats. 


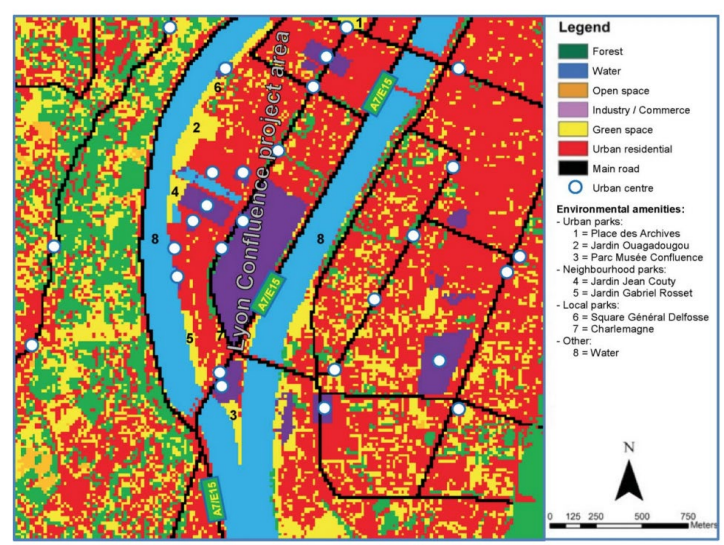

(Land use in and around the Lyon Confluence project area (based on EVA 2009. Source: Roebeling, P., Saraiva, M., Palla, A., Gnecco, I., Teotonio, C., \& Fidelis, T. (2017). Assessing the Socio-economic Impacts of Green/Blue Space, Urban Residential and Road Infrastructure Projects in the Confluence (Lyon): A Hedonic Pricing Simulation Approach. Journal of Environmental Planning and Management,60(3-4), 482-499. https://doiorg.proxy.library.cornell.edu/http://www.tandfonline.com/loi/cjep20)

The results of the study pointed out that the areas under the Lyon Confluence project had experienced huge increases in population, the value of the retail housing, and the overall real estate value. People with middle and high incomes were found more willing to reside in this area, though with smaller living spaces, and relatively higher housing value with closer distances to urban parks. As for people with lower incomes, they were less willing to accept a higher value of real estate with proximity to a new urban park. Therefore, the value of urban green spaces would bring more compact regions of households living; population density increased as more households got attracted to concentrated regions. Besides, the value and prices of housing would appreciate, and the wealth of residents would increase in attractive areas.

However, the extent of the value-added depended on the quality and size of the intervention made by the project, the places relative to existing residential areas, urban centers, road infrastructure, and environmental amenities, as well as the social classes attracted to the intervention area (Roebeling et al, 2017). Similar findings were conducted by Plantinga (2003) and Wu (2006), suggesting the most attractive population fell into high-income households, especially with the large income gap between the rich and the poor. Additionally, past studies pointed out that the construction of green space would result in not only the enhanced real estate prices, also the gentrification and the displacement of lower-income households (Wolch, Byrne, and Newell, 2014). Such an argument is reasonable when thinking in terms of the concentration of wealth. People care about housing value, housing prices, in addition to the surrounding class of neighbors. This is one of the important factors in housing selection, which impacted the social quality in residential areas. Once high-income people get attracted to certain regions, which later followed by the same social classes, the value of the real estate would appreciate naturally. The benefits of getting from the proximity to open green space were in the largest in the first place. As time went by, other factors came into play and affected the housing prices and value beyond the wealth distribution of the residents.

Furthermore, in valuing the individual characteristics and the multifunctionality of urban green spaces, Czembrowski, et al used the integrated method of sociotope mapping and the hedonic pricing model to estimate the impact of the urban green spaces given to the housing prices in Stockholm in Sweden. With more informed knowledge of the green spaces and ecosystem services valuation, the general public and the stakeholder paid more attention to the development, maintenance, and preservation of green land usage and infrastructure. The multifunctionality of the urban green land usage included the various aspects of benefits, different levels of service could provide, and the many methods urban green space could be used by inhabitants and policymakers. Valuing the marketable and economic benefits of urban green space, Czembrowski, et al raised a method that was built on the original hedonic pricing model to study the different characteristics of environmental amenities using the nonmonetary valuation method of Geographic Information System (GIS) (Czembrowski, et al, 2019). 
Czembrowski pointed out that since the hedonic pricing model was used to analyze the specific characteristics of urban green spaces, not all the characteristics received the same effect. For instance, the existence of cemeteries would bring a negative impact on the real estate price. Similarly, not all the characteristics of green spaces would be preferred for stockholders in Stockholm. Based on the results of the study, the most desirable features of green spaces were those designed for aesthetic purposes. The weakest impact on the housing price was the attribute of nature, meaning the real estate values in Stockholm would not be influenced a lot for those green spaces designed with a natural purpose. A similar finding was obtained in Jinan City in China, with the scenery forests becoming the more favored attributes of the green space that people cared about when purchasing a home (Kong, Yin, and Nakagoshi, 2007).

\subsection{UNITED STATES}

The ecosystem services and environmental amenities were often neglected in the city planning and policymaking in the United States due to the difficulties in evaluating the economic and sustainable benefits. The application of hedonic pricing models was conducted to capture the value of some cultural ecosystem services, including local aesthetic quality, accessibility to outdoor recreational areas, and associated services in Dakota County, in the Twin Cities metropolitan area (TCMA) of Minnesota. The property values were found to be correlated with open space by generating outdoor recreation and aesthetic view values (Sander and Haight, 2012). According to the studies done by Crompton in the year 2001, there are about 30 studies done on the impact of public parks on residential property values, resulting in a positive relationship between parks and property values (Crompton, 2001). In terms of scenic quality, many previous studies indicated that the quality of the views was positively associated with the surrounding residential home values (Bourassa et al, 2004).

As for the model application, the hedonic pricing model was used to estimate the economic value of the ecosystem services based on the prices of properties. Sander and Haight concluded that the pricing of certain properties was positively associated with the increased view areas and views of water and lawn, higher accessibility of outdoor recreational areas, and higher coverage of neighborhoods' trees. Decreasing the distance between comes and lakes, however, would increase the home sale prices. The possible reason might be due to limited accessibility for city residents to large lakes and parks from their homes. Increased walkability would be generated instead, resulting in stronger desirability to the need for open areas. One of the benefits of the study is to provide good insights to the policymakers over the questions of land-use planning and economics valuation of ecosystem services. By applying the values calculated by the hedonic pricing model, measuring adequate distances between homes and the proximity to open space areas seems important. Such consideration and planning would help to achieve maximizing property values while keeping sustainable land-use practices and designs in the process of urbanization (Sander and Haight, 2012).

At the same time, Sander and Haight argued about the limitations of the hedonic pricing model and some cautions that should be considered when applying the model into the study. There might be the possibility of underestimating some parts of the ecosystem services values. For instance, the benefits of getting from tourism, and the profits from the production of marketable goods would also be considered. Some aspects of the values might be double-counted into the model (Sander and Haight, 2012).

After drawing samples from 1789 metropolitan area census tracts from the state of Michigan in the United States, the results of the study suggested that there existed constraints from the supply side of the analysis that bidding up the prices of the real estate and reducing the growth of population located in residential areas. To be more specific, public lakes and other state-opened space, including areas other than public parks, wildlife reserves, forests, and recreational purpose lands, could result in bidding up prices, which in the end, have fewer people willing to migrate to nearby regions. In other words, the existence of a lake had impacts over the raising property value and reduction in the quantity and quality of neighboring tracts (Sander and Haight, 2012).

Meanwhile, another crucial term that is related to the valuation of ecosystem services is urban open space, other than green space. The benefits getting from urban open space were huge, by providing services to the urban populations over the recreational, aesthetic, and agricultural opportunities. Besides, not only people living nearby the urban open space would receive benefits in the short term, future generations could seize the values from developing and preserving these spaces. There was lacking policy intervention in the United States, reflected by the number of votes casted that dealt over the issues of open space conservation at the unit of state, country, and district 
An Analysis of Common Applications on Hedonic Pricing Model in Valuing Ecosystem Services: Similarities and Difference Between Europe, Us, And China

level. The problem turned out to be the lack of informed knowledge on the value of services provided by urban open spaces as well as their opportunity costs of preservation. Without sufficient information on the trade-off between the value of the services gained from the urban open space, either that's marketable and non-marketable valuation, against the cost of maintenance and preservation. Since a lot of the time, identifying the transferrable value in the market was not easy, policymakers would not draw enough attention to this issue (Brander and Koetse, 2011).

A meta-analysis was conducted by Brander and Koetse in the year of 2011, focusing on the additional consumer preferences for urban and peri-urban open space, where the peri-urban open space referred to the areas that were immediately adjoining an urban area. After collecting 38 contingent valuation studies and the hedonic pricing studies on urban and peri-urban open space, Brander and Koetse argued that, in terms of the hedonic pricing analysis, as the dependent variable in the meta-analysis, the changing unit of the property value was based on 10 meters decrease in the proximity to the closest open space using the money value in 2003 . The results were an increase in housing prices for about 0.1 percent, indicated from the sample of the primary studies. To be more specific, when the distance to the closest open space increased, the impact on the housing price reduced (Brander and Koetse, 2011). One thing worth noting is that, among the characteristics of aesthetics, preservation, and recreational opportunities, the economic value of the green space would only generate a noticeable increase with the latter two, except for the aesthetics characteristic of the green space design. Such findings did not align with the argument made by Czembrowski, et al (Czembrowski, et al, 2019).

In a more general discussion, the city design in the United States is quite different from those in some Asian countries. In terms of many cities, open space, green space, or environmental amenities would be found surrounded in some city centers. For instance, many parks in New York City fell into the middle of the regions where people clustered. Other than that, people would be able to get access to public parks from their home, with convenient transportation methods. Therefore, the benefits and the services obtained in large cities were more interrelated with people and other open resources. While in some country-side regions, those open spaces might be surrounded by multi-directional highways. To get access from home, people would have to choose by driving private vehicles. The areas of open space seemed to be more concentrated and had higher proximity to residential areas.

Such design is quite different from those in China; most of the parks and other urban open-spaces were consistent with the country-side design in the United States. People would have to drive private cars to the closest green space and urban open space. For those getting close to the residential regions, many of them were designed and constructed many years ago, since the value of the land and the scarcity of households limited the regions of real estate that could be made around the open space. These days, more and more people moved far away from the city center and recited into the residential areas with limited services available. That might due to the enhanced average household income in China, resulting in the percent of household ownership of private vehicles increased, and people weighted relatively less on the proximity to the closest public open spaces compared to those in the past. The willingness and self-wishes in the demand for urban open space might come into play.

\subsection{CHINA}

The cities in the United States, the valuation of green space, as well as the impact brought on the pricing in the real estate market are studied in various scopes. The transferrable values and the environmental benefits getting from the urban green space were not easy to be captured in the open market. Many policymakers and city planners faced difficulties in improving the quality of urban green space due to the lack of noticeable trade-off advantages. The hedonic pricing model, therefore, was applied to capture and measure the values of the non-market priced recreational, aesthetic, environmental, and agricultural resources for the sake of the general public and society. Kong, Yin, and Nakagoshi pointed out in the year of 2006 that, there existed a wide and complex range of factors impacting the value prices of the property, including the housing design and structure, quality of people living in the neighborhood and the characteristics of the neighborhood environment, accessibility to the Central Business District (CBD), and the surrounding environmental amenities that helped to bring values to the property (Kong, Yin, and Nakagoshi, 2006).

The number of studies that had been done in the past over the valuation of urban green spaces in Mainland China was lacking, which might be due to the complex market pricing in the real estate market; the hedonic pricing model application was limited (Wang and Huang, 2005). 


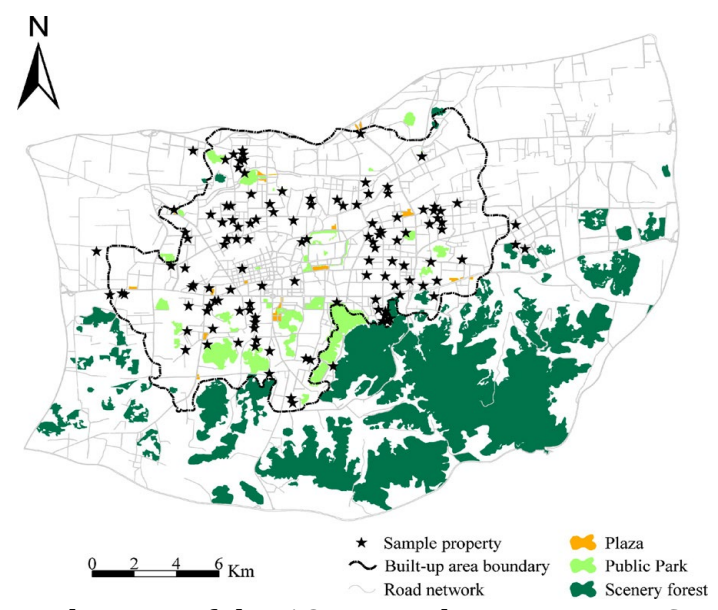

(The study area and geographic distribution of the 124 sample properties. Source: Kong, F., Yin, H., \& Nakagoshi, N. (2007). Using GIS and landscape metrics in the hedonic price modeling of the amenity value of urban green space: A case study in Jinan City, China. Landscape \& Urban Planning, 79(3/4), 240.)

After collecting 124 housing clusters in Jinan City in China, located within the urban areas, Kong, Yin, and Nakagoshi suggested that the hedonic pricing model could improve by adding the analysis using the GIS and landscape metrics. The results of the study found the housing price was associated with a reduction in the accessibility to the scenery forest. Meanwhile, an increase in housing prices would occur with larger size and distance to the scenery forest, better design, and quality of green space. To some extent, people would be in favor of closer proximity to the green housing districts and easier accessibility to the scenery forest areas. However, necessary attention should be drawn considering the number of people relocating into residential areas that were close to open green space and the preservation of the open environmental amenities; since based on the finding, the population density would become more concentrated which further impacting the development, maintenance, and the preservation of the green spaces. Additional, new green space programs and the exploitation of the new residential areas could draw some attention to such finding, that in line with previous studies on the significant positive effects on housing prices impacting from the economic value of the urban green space and environmental amenities (Kong, Yin, and Nakagoshi, 2007).

Looking at other cities in China, Shenzhen, for instance, in terms of evaluating the influence of urban green space on the residential housing prices, $\mathrm{Wu}$, et al used the GIS approach and hedonic pricing model to capture the effect of public resources on the value of the properties, especially green space in the year of 2015.

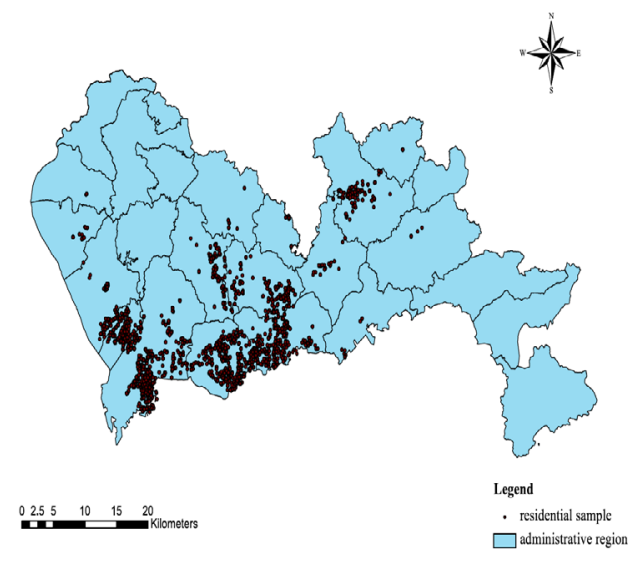

(Study area and geographic distribution of sample properties (data from SOFANG 1999) Source: Wu, J., Wang, M., Li, W., Peng, J., \& Huang, L. (n.d.). Impact of Urban Green Space on Residential Housing Prices: Case Study in Shenzhen. JOURNAL OF URBAN PLANNING AND DEVELOPMENT, 141(4). https://doiorg.proxy.library.cornell.edu/10.1061/(ASCE)UP.1943-5444.0000241) 
The collecting transaction price of 6494 units in the Shenzhen real estate trading center, Wu et al, pointed out that the impact of the urban public resources on the housing prices was shown statistically significant, with the greatest importance over the distance to the central business district, and the worst importance over the distance to the subway station. Shenzhen, unlike some other cities in China, is composed of small sectors of sub-central business districts scattering out, therefore; such impact would vary over various populations living in different residential areas. In other words, the importance of the proximity to the city center might not be the same for all individuals located in diverse regions in Shenzhen. Besides, the distance to public parks was founded, having the second-largest impact on the housing price. The increase in the distance to the parks would diminish in the extent of the effect and became constant as the distance increased (Wu, et al, 2015).

In considering the consequences of the environmental services in China, one of the important elements in the ecosystem services was the urban design of forests. The development of urban greening in China could be traced back many decades ago. Within the increasing attention and public awareness of preserving and managing the green space in these years, Jim and Chen argued about three factors involved in the study or urban forests, including the design and construction of urban forest, evaluation and assessment of the ecosystem services, and the management and planning of the forest. All three elements interrelated to the short term and long-term sustainable growth of urban forest planning in China (Jim and Chen, 2009).

Past literature indicated that the influence over the ecosystem services brought out contained various components to balance the carbon emission in the air, reduce air pollution, and noise pollution (Jim and Chen, 2009). Additionally, it also carried out an impact on regulating the microclimate, recreational opportunities, and environmental amenities, which further shaping the sustainable growth of the environment and the quality of living for the population (Jim and Chen, 2006). The results of the study pointed out the lack of methods that could be used to measure the ecosystem services generated by urban forests, suggesting improvements over the methods of evaluating the high level of benefits getting from the environmental services, and improving in the data collection process and requirement in the valuation of ecosystem services by the region of urban forests, while associating with the urban green space, and urban green system planning and management (Jim and Chen, 2009).

As the economic development and living conditions improved in China, people valued additional factors when purchasing houses; urban green spaces were one of the elements being considered. With the rapid urbanization, larger areas of the land could be used as the potential resources for residential area exploitation, both in the city centers and country-sides. The tendency in the real estate market was inclined with settlement in cities that were closer to the wide ranges of environmental and recreational resources. Though the general size of the public green space was smaller compared to those in the country-side, people still placed convenience on commuting in the most or second most crucial role. Many people who migrated and relocated to big cities tended to reply to public transportation other than private vehicles. Not only due to the consideration of the costs of transporting but also on the avoidance of traffic jams. The recent trend in the real estate market, however, shifted to the housing selection in country-side regions. People value and get more attention to the benefits of the urban green spaces nearby the residential areas. The greater proximity to the open green space for countryside housing was associated with the improvement in economic freedom and self-willingness to the accessibility of environmental services. However, such impact and considerations varied across different parts of the cities in China.

Guangzhou, located in the southern part of China, had been studied on the impacts of the urban environmental elements on the housing prices by Jim and Chen in the year of 2005. The government's administrative allocation and management system of real estate could be traced back to the middle and the end of the twentieth century. After this period of time, public housing came into play which brought difficulties in the design and construction of residential housing. To find out the extent of the impact of the urban green spaces and environmental amenities on the price of the properties in Guangdong, the hedonic pricing model was used in the study. The results suggested that the application of the hedonic pricing model could somehow capture the changes in the housing price that the distances to the water areas and green spaces would generate an increasing impact on the surrounding housing price. 


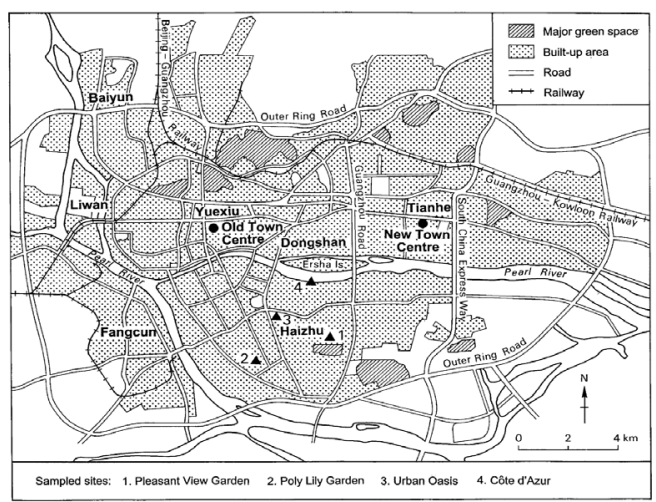

(Map of the central core area of Guangzhou city showing the locations of the four sampled residential housing developments. (Source: Jim, C. Y., \& Chen, W. Y. (2006). Impacts of urban environmental elements on residential housing prices in Guangzhou (China). Landscape and Urban Planning, 78(4), 422-434. https://doiorg.proxy.library.cornell.edu/10.1016/j.landurbplan.2005.12.003)

What's more, the impact of getting from the proximity to the wooded region was limited, as well as the existence and intensity of traffic noise. This means, either people received a high level of tolerance on the noise generated by transportation, or they were used to it when selecting residential areas, especially in large cities (Jim and Chen, 2005). Nevertheless, given the fact that the tendency for housing selection generally shifted to the countryside suggested a reasonable argument that, if people faced options of living far away from the noisy regions, they would choose to relocate. As for population lived and worked areas that were difficult to avoid such environmental externalities, they would not take serious importance when purchasing houses.

In 2007, Jim and Chen focused instead on the consumption preferences and environmental externalities in Guangzhou. The local housing preferences served as complex and changing topics in the real estate market. The broad macroeconomic environment and the social opportunities related to housing selection were not the same depending on the time and place in Chinese society. In terms of trend and growth in the housing market, the attention and focus shifted based on public policies and personal preferences. Yet, all the elements were interrelated, and people valued environmental services which helped in the short-term satisfaction of living in suitable residential areas, and the long-term potential left to the future generations (Jim and Chen, 2007).

The hedonic pricing model suggested in the study that green space generated a positive impact on the development of local amenities, landscape, and recreational opportunities. Homebuyers, therefore, would be willing to make the selection on real estate containing such factors. Moreover, since 1998, the open market strategies applied with the removal of the subsidized housing allocation system, Chinese consumers faced drastic changes and challenges in the supply and demand sides in housing market prices. In Guangzhou, the findings of the study argued that the most desirable change the people were looking for was the improvements over the floor area and the living conditions, with the biggest determining factor of the housing price. Internal influencing factors were found relatively less important compared to the external influencing factors. The biggest rated important element was the quality of the property management, and surprisingly, people cared a lot for the safety and security design of the residential housing. That might be caused by the increasing disturbance in social activities and dissatisfaction with the laws in Guangzhou. Among areas located in major cities, distance to grocery stores, level of convenience in commuting, and accessibility of public transportation were found crucial. Within areas further from the major cities, people valued more on the quality of the environmental services, and the safety design of the residential areas. However, proximity to the metro station and schools were founded within less importance. (Jim and Chen, 2007).

But the importance of the proximity to schools differed within various regions in China. As for the cultural factors in Chinese society, young people would tend to choose to live with their parents. When they start with their own business and jobs, they might get the chance to move into large cities in search of a wide range of job opportunities and recreational services. In that case, they might put the attention more over the proximity to the open green space, and the urban open spaces while selecting houses. Therefore, real estate sellers would then emphasize the benefits combined within the urbanized and environmental services available in larger cities. One thing important for people to think about is the distance to school. As for families having young kids that were thinking about school attainment, this became the most crucial determining factor. 
In the recent Chinese society, even the quality of housing was poor in some places, people were still willing to purchase for a high price. That's when the idea of Hukou came into play. Hukou means the official registration of residents in certain regions. Only after having an official Hukou status, kids are then able to attain school, get medical care, insurance care, as well as some other social services. For those schools with high demand, parents have surged to purchase houses nearby the school. In that case, if they are having the registered Hukou, and able to live close to school, those families would then receive higher chances of getting accepted by the school due to the excessive demand. The determining factors in the housing selection process, environmental services would not play as crucial roles, instead; more cultural and social elements were those factors people really cared about.

\section{CONCLUSIONS}

In conclusion, similarities and differences existed in the application of hedonic pricing models associated with various historical and cultural backgrounds. Thinking back to the current global housing market, under the epidemic of COVID-19, many countries and regions have undergone challenges on the macroeconomics downturn, resulting in a large number of people getting unemployed and even becoming homeless. For a short period, people would value more on the problem of surviving. But after the end of the crisis, there is still a high chance to value back the benefits generated from the environmental services. In those cases, the hedonic pricing model could be used to value the ecosystem services payments.

\section{SOURCES OF FUNDING}

This research received no specific grant from any funding agency in the public, commercial, or not-for-profit sectors.

\section{CONFLICT OF INTEREST}

The author have declared that no competing interests exist.

\section{ACKNOWLEDGMENT}

None.

\section{REFERENCES}

[1] Anderson, S. T., \& West, S. E. (2006). Open space, residential property values, and spatial context. Regional $\begin{array}{llll}\text { Science and Urban } \quad \text { Economics, } & \text { 773-789. } & \text { https://doi- }\end{array}$ org.proxy.library.cornell.edu/10.1016/j.regsciurbeco.2006.03.007

[2] Bourassa, S. C. (1), Sun, J. (1), \& Hoesli, M. (2,3). (n.d.). What's in a view? Environment and Planning A, 36(8), 1427-1450. https://doi-org.proxy.library.cornell.edu/10.1068/a36103

[3] Brander, L. M., \& Koetse, M. J. (2011). The value of urban open space: Meta-analyses of contingent valuation and hedonic pricing results. Journal of Environmental Management, 92(10), 2763-2773. https://doiorg.proxy.library.cornell.edu/10.1016/j.jenvman.2011.06.019

[4] Crompton, J. (2001). The impact of parks on property values: A review of the empirical evidence. JOURNAL OF LEISURE RESEARCH, 33(1), 1-31.

[5] Czembrowski, P., \& Kronenberg, J. (2016). Hedonic pricing and different urban green space types and sizes: Insights into the discussion on valuing ecosystem services. Landscape and Urban Planning, 146, 11-19. https://doi-org.proxy.library.cornell.edu/10.1016/j.landurbplan.2015.10.005

[6] Czembrowski, P., Łaszkiewicz, E., Kronenberg, J., Engström, G., \& Andersson, E. (2019). Valuing individual characteristics and the multifunctionality of urban green spaces: The integration of sociotope mapping and $\begin{array}{lllll}\text { hedonic } & \text { pricing. } & \text { PLoS } & \text { 14(3), } & \text { https://doi- }\end{array}$ org.proxy.library.cornell.edu/10.1371/journal.pone.0212277 
[7] David R. Lee (2020). Lecture 5.2: Valuation of Ecosystem Services [PowerPoint slides]. Retrieved from Cornell University AEM 6600 Natural Resources and Economic Development.

[8] [8Elena G. Irwin, P. Wilner Jeanty, \& Mark D. Partridge. (2014). Amenity Values versus Land Constraints: The Spatial Effects of Natural Landscape Features on Housing Values. Land Economics, 90(1), 61.

[9] Jim, C. Y., \& Chen, W. Y. (2006). Impacts of urban environmental elements on residential housing prices in Guangzhou (China). Landscape and Urban Planning, 78(4), 422-434. https://doiorg.proxy.library.cornell.edu/10.1016/j.landurbplan.2005.12.003

[10] JIM, C.., \& CHEN, W. (2007). Consumption preferences and environmental externalities: a hedonic analysis of the housing market in Guangzhou. Geoforum, 38(2), 414-431.

[11] Jim, C. Y., \& Chen, W. Y. (2009). Ecosystem services and valuation of urban forests in China. Cities, 26(4), 187194. https://doi-org.proxy.library.cornell.edu/10.1016/j.cities.2009.03.003

[12] Kong, F., Yin, H., \& Nakagoshi, N. (2007). Using GIS and landscape metrics in the hedonic price modeling of the amenity value of urban green space: A case study in Jinan City, China. Landscape \& Urban Planning, 79(3/4), 240.

[13] Lutzenhiser, M., \& Netusil, N. R. (2001). The Effect of Open Spaces on a Home's Sale Price. Contemporary Economic Policy, 19(3), 291. https://doi-org.proxy.library.cornell.edu/10.1093/cep/19.3.291

[14] Roebeling, P. C. (1), Fletcher, C. S. (1), Hilbert, D. W. (1), \& Udo, J. (2). (n.d.). Welfare gains from urbanizing landscapes in Great Barrier Reef catchments? A spatial environmental-economic modelling approach. WIT Transactions on Ecology and the Environment, 102, 737-749. https://doiorg.proxy.library.cornell.edu/10.2495/SDP070712

[15] Roebeling, P. (1), Saraiva, M. (1), Fidelis, T. (1), Palla, A. (2), Gnecco, I. (2), Teotónio, C. (3), Martins, F. (3), Alves, H. (3), \& Rocha, J. (3). (n.d.). Assessing the socio-economic impacts of green/blue space, urban residential and road infrastructure projects in the Confluence (Lyon): a hedonic pricing simulation approach. Journal of Environmental Planning and Management, 60(3), 482-499. https://doiorg.proxy.library.cornell.edu/10.1080/09640568.2016.1162138

[16] Sander, H. A., \& Haight, R. G. (2012). Estimating the economic value of cultural ecosystem services in an urbanizing area using hedonic pricing. Journal of Environmental Management, 113, 194-205. https://doiorg.proxy.library.cornell.edu/10.1016/j.jenvman.2012.08.031

[17] Tse Raymond Y.C., \& Love Peter E.D. (2000). Measuring residential property values in Hong Kong. Property Management, 18(5), 366-374. https://doi-org.proxy.library.cornell.edu/10.1108/02637470010360669

[18] Wolch, J., Byrne, J., \& Newell, J. (2014). Urban green space, public health, and environmental justice: The challenge of making cities "just green enough."

[19] Wang, D., Huang,W.S., 2005. Hedonic house pricing method and its application in urban studies. Urban Plann. 29 (3), 62-71.

[20] Wu, J., \& Plantinga, A. J. (2003). The influence of public open space on urban spatial structure. Journal of Environmental Economics and Management, 46(2), 288-309. https://doiorg.proxy.library.cornell.edu/10.1016/S0095-0696(03)00023-8

[21] Wu, J. (2006). Environmental Amenities, Urban Sprawl, and Community Characteristics. Journal of Environmental Economics and Management, 52(2), 527-547. https://doi org.proxy.library.cornell.edu/http://www.sciencedirect.com/science/journal/00950696

[22] Wu, J., Wang, M., Li, W., Peng, J., \& Huang, L. (n.d.). Impact of Urban Green Space on Residential Housing Prices: Case Study in Shenzhen. JOURNAL OF URBAN PLANNING AND DEVELOPMENT, 141(4). https://doiorg.proxy.library.cornell.edu/10.1061/(ASCE)UP.1943-5444.0000241

[23] Zhang, Y., \& Dong, R. (n.d.). Impacts of Street-Visible Greenery on Housing Prices: Evidence from a Hedonic Price Model and a Massive Street View Image Dataset in Beijing. ISPRS INTERNATIONAL JOURNAL OF GEOINFORMATION, 7(3). https://doi-org.proxy.library.cornell.edu/10.3390/ijgi7030104. 